protein) and patient reported parameters (e.g. BASDAI, ASDAS) were collected. X-rays were evaluated according to the modified New York (mNY) criteria for sacroiliitis. The clinical axSpA diagnosis was made by the rheumatologist. Patients were either diagnosed with 'definite SpA', 'suspicion of SpA' or 'no suspicion of SpA', based on the clinical assessment. Patients with 'definite SpA' were classified into radiographic or non-radiographic axSpA according to the ASAS criteria. Patients were treated according to standard care guidelines.

Results: Between April 2017 and October 2018, 65 patients were referred to the Rheumatology clinic, of whom 50 (mean age 42 years; $48 \%$ female; median back pain duration 15 years) met all inclusion criteria. AxSpA was diagnosed in 13 patients (26\%), of whom seven fulfilled the criteria for radiographic and six for non-radiographic axSpA (table 1). Another 21 patients (42\%) were considered clinically suspicious for early axSpA, of whom four had SI joint abnormalities and two even fulfilled the $\mathrm{mNY}$ criteria for sacroiliitis. Forty-two\% of all patients had a high disease activity score (ASDAS $\geq 2.1$ ). Patients diagnosed with axSpA were significantly more often male and HLA-B27 positive, had more SpA features and a higher BASMI score. In 25 patients treatment was started, mostly with nonsteroidal anti-inflammatory drugs. Two patients received a tumor necrosis factor inhibitor shortly after diagnosis.

Conclusion: In this study, $26 \%$ of the patients referred with noninfectious AAU and chronic back pain ( $\geq 3$ months, started < age of 45 years) were newly diagnosed with axSpA. Furthermore, another $40 \%$ required further follow up because of a suspicion for beginning axSpA. These results stress the importance of systematic referral of AAU patients with chronic back pain from the ophthalmologist to the rheumatologist, to improve early recognition of axSpA.

Disclosure of Interests: Rianne van Bentum: None declared, Frank Verbraak: None declared, Sanne Wolf: None declared, Jenny Ongkosuwito: None declared, Stevie Tan: None declared, Irene van der Horst-Bruinsma Grant/research support from: MSD, Pfizer, AbbVie, Consultant for: Abbvie, UCB, MSD, Novartis, Speakers bureau: BMS, AbbVie, Pfizer, MSD DOI: 10.1136/annrheumdis-2019-eular.805

\section{SAT0354 CARDIVASCULAR RISK IN YOUNG PATIENTS WITH LOW AXIAL SPONDYLOARTHRITIS ACTIVITY: PROMISING SCORING TOOLS}

Elizaveta Vasilenko ${ }^{1}$, Olga Nikolaeva ${ }^{1}$, Anna Dadalova ${ }^{1}$, Maxim Korolev ${ }^{2}$, $\checkmark$ Mazurov ${ }^{1}$, Inna Gaydukova ${ }^{1} .{ }^{1}$ North-Western State Medical University named after I.I. Mechnikov, Department of Therapy, Rheumatology, Examination of Temporary Disability and Quality of Medical Care named after E.E.Eichwald, St. Petersburg, Russian Federation; ${ }^{2}$ The Federal Research Center Institute of Cytology and Genetics, The Siberian Branch of the Russian Academy of Science, Novosibirsk, Russian Federation

Background: Patients (pts) with axial spondyloarthritis (axSpA) have increased cardiovascular morbidity and mortality, compared to the general population. However, assessment of cardiovascular risk (CVR) in axSpA is complicated, as in age $<40$ years conventional CVR scales (SCORE, ets.) are not recommended, as conventional risk factors do not completely determine an increased CVR. The QRESEARCH Cardiovascular Risk Algorithm (QRISK) is the only scale of measuring probability of major cardiovascular events in pts aged 25 to 40 .

Objectives: To measure CVR in young pts with low activity of axSpA, and to evaluate the interrelation between CVR, measured with QRISK and gene predisposition.

Methods: The study included 46 pts $25-40$ years old with axSpA (ASAS criteria 2009), achieved inactive disease on TNF- $\alpha$ inhibitors. AxSpA activity was measured with ASDAS and BASDAI. CVR was calculated with the modified QRISK (QRISK3) (https://qrisk.org/three/). All parameters of QRISK3 were collected: smoking and diabetes statuses, angina or heart attack in a $1^{\text {st }}$ degree relative $<60$, chronic kidney disease (3-5 stage), atrial fibrillation, blood pressure, migraines, rheumatoid arthritis, systemic lupus erythematosus, severe mental illness, atypical antipsychotic medication, regular steroid tablets usage, erectile dysfunction, cholesterol/HDL ratio, systolic blood pressure, Standard deviation (SD) of at least two most recent systolic blood pressure readings $(\mathrm{mmHg})$, height $(\mathrm{cm})$, weight $(\mathrm{kg})$. Gene polymorphisms to main cytokines of axSpA and atherosclerosis pathogenesis were measure (IL17A-197, IL17F7 His/Arg, IL17F-11139 c/g, TNF-863, TNF-308, TNF-238, IL1B-31, IL4-590, IL6-174, IL10-1082, IL10-592, VEGF-2578, VEGF936, MMP2-1306, MMP3-5A6A, MMP9-1562).
To identify the relationship between genetic factors and clinical characteristics an exploratory factor analysis was performed.

Results: Mean age \pm SD of included pts was $32.5 \pm 3.87$ years (26\% of pts aged $25-30,28.3 \%$ - 30-35, 28.3\% - 35-40 years), 36 (78.3\%) patient were male, symptoms duration $8.71 \pm 4.72$ years, duration of TNF- $\alpha$ inhibitor treatment $3.1 \pm 2.4$ years, ASDAS $1.95 \pm 1.23$, BASDAI $1.4 \pm 0.8$. All three age groups were comparable $(p \geq 0.05)$. Out of the 46 pts $25-40$ years old $34(75.6 \%)$ had a low CVR and $11(23,9 \%)$ had increased CVR (fig.1). Average QRISK3 score of all the patients was $1.18 \pm 1.64 \%$. In the 25-30 year old age QRISK3 was $1.51 \pm 0.25 \%$, in pts $30-35 y e a r s$ old $-1.09 \pm 0.6 \%$, in $35-40$ years old $-2.31 \pm 1.0 \% \quad(p<0.05$ for the intergroup difference).

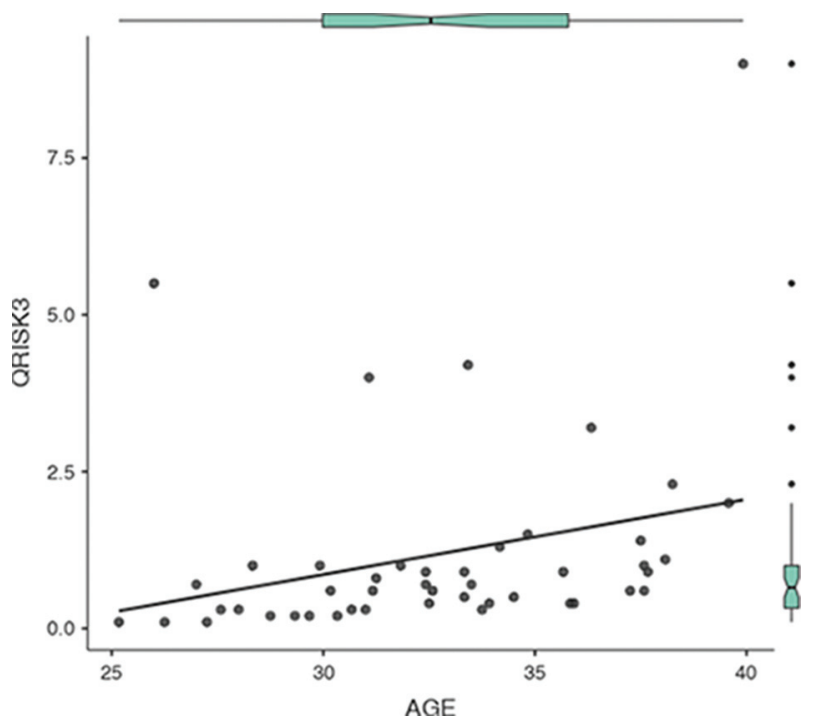

All patients with increased CVR had a direct associations with homozy gous in CC allele IL17F-11139 gene, heterozygous in GA allele of TNF308 and heterozygous in CG allele IL6-174. Negative associations were found between CVR and heterozygosity in His/Arg and homozygous in $\mathrm{His} / \mathrm{His}$ of IL17F7, homozygosity in GG allele TNF-308, homozygosity in CC IL6-174, table 1. Interrelation of CVR with another gene polymorphisms was not significant (data are not present).

Table 1. Interrelation of QRISK 3 and Gene polymorphisms - exploratory factor analysis with 'varimax' rotation.

\begin{tabular}{|c|c|c|c|c|c|c|c|c|c|}
\hline$\underset{3}{\text { QRISK }}$ & $\begin{array}{c}1 \mathrm{IL17F} . \\
11139 \\
\mathrm{CC}\end{array}$ & $\begin{array}{c}11139 \\
\text { CG }\end{array}$ & & & & 1116. & $\begin{array}{c}116 \cdot 174 \\
C G\end{array}$ & & \\
\hline & 0.830 & .0 .830 & & & & .80 & 0.945 & 9.935 & \\
\hline
\end{tabular}

Conclusion: A quarter of young axSpA pts had an increased 10-year probability of cardiovascular events. Gene polymorphisms in IL-6, IL17F, and TNF- $\alpha$ locuses are strongly associated with increased CVR. QRISK3 and gene polymorphisms could be promising tools in CVR assessment in axSpA.

Further larger studies are needed for evaluation of CVR factors in axSpA.

\section{REFERENCE}

[1] Julia Hippisley-Cox, et al. BMJ 2017; 357 doi: https://doi.org/10.1136/bmj. j2099.

Disclosure of Interests: Elizaveta Vasilenko: None declared, Olga Niko laeva: None declared, Anna Dadalova: None declared, Maxim Korolev: None declared, V Mazurov Grant/research support from: JSC BIOCAD, Inna Gaydukova Grant/research support from: JSC BIOCAD, Speakers bureau: paiment from Pfizer, Novartis, Abbvie, Biocad, Selgene, MSD, Sanofy does not exceed 10000 euros

DOI: 10.1136/annrheumdis-2019-eular.6009 